\title{
INTERFERENSI FONOLOGIS BAHASA MUNA DALAM PENGGUNAAN BAHASA INDONESIA LISAN SISWA MTS KAROLEMBO DI KABUPATEN MUNA
}

\author{
Sarmawati, ${ }^{1}$ Sri Suryana Dinar, ${ }^{2}$ La Ino ${ }^{3}$ \\ pbsi.fkip.uho@gmail.com \\ 1,2,3, Jurusan Pendidikan Bahasa dan Sastra Indonesia, \\ Fakultas Keguruan dan Ilmu Pendidikan, Universitas Halu Oleo \\ Kampus Hijau Bumi Tridharma Anduonohu, Kendari, Indonesia
}

\begin{abstract}
ABSTRAK
Tujuan dalam penelitian ini yaitu untuk mendeskripsikan bentuk interferensi fonologis bahasa Muna yang terjadi dalam penggunaan bahasa Indonesia lisan siswa MTs Karolembo di Kabupaten Muna dan untuk mengetahui faktor apa yang menyebabkan terjadinya interferensi fonologis yang dilakukan oleh siswa MTs Karolembo di Kabupaten Muna. Penelitan ini merupakan penelitian lapangan. Metode yang digunakan dalam penelitian ini adalah deskriptif kualitatif. Sumber data dalam penelitian ini adalah siswa MTs Karolembo yang melakukan interferensi dalam berbicara. Teknik pengumpulan data yang digunakan dalam penelitian ini adalah teknik catat dan rekam. Selanjutnya data dianalisis dengan menggunakan pendekatan deskriptif kualitatif dengan langkah mentranskripsi data, mengidentifikasi data, dan reduksi data. Berdasarkan hasil penelitian dapat disimpulkan bahwa Interferensi Fonologis Bahasa Muna dalam Penggunaan Bahasa Indonesia Lisan Siswa MTs Karolembo di Kabupaten Muna meliputi penghilangan fonem di tengah suku kata, di akhir suku kata, dan perubahan fonem.
\end{abstract}

Kata Kunci: interferensi; fonologis; bahasa Muna; lisan 


\section{PENDAHULUAN}

\subsection{Latar Belakang}

Dalam kehidupan bermasyarakat seseorang tidak mungkin hidup tanpa kehadiran orang lain atau tanpa bergaul dengan orang lain. Hal ini membuktikan bahwa pada hakikatnya manusia merupakan makhluk sosial. Sebagai makhluk sosial, manusia secara naluriah terdorong untuk bergaul dengan manusia lain, baik untuk menyatakan keberadaan dirinya, mengespresikan kepentingannya, menyatakan pendapatnya, maupun mempengaruhi orang lain demi kepentingannya sendiri, kepentingan kelompok, atau kepentingan bersama.

Bangsa Indonesia sebagai salah satu bangsa yang multi etnik sehingga diasosiasikan bahwa warga Negara Indonesia pada umumnya paling sedikit menggunakan dua bahasa, yaitu bahasa daerah (BD) atau bahasa ibu dan bahasa Indonesia (BI) dalam interaksi budayanya. Bahasa daerah berfungsi sebagai alat komunikasi antarwarga sesuku, meskipun dalam kegiatan komunikasi tertulis sebagian besar menggunakan bahasa Indonesia.

Dalam ilmu linguistik penutur yang menggunakan dua bahasa secara bergantian dalam kehidupana sehari-hari di namakan dwibahasawan. Menurut Tarigan (1988: 2) "dwibahasawan adalah orang yang dapat berbicara dalam dua bahasa".

Berdasarkan peta, sekolah MTs Karolembo merupakan salah satu sekolah yang terdapat di Desa Lembo, Kecamatan Kontukowuna, Kabupaten Muna, Provinsi Sulawesi Tenggara. Sekolah MTs Karolembo merupakan salah satu sekolah yang memiliki siswa mayoritas suku Muna, dan menggunakan bahasa Muna sebagai bahasa sehari-hari.

Pada umumnya siswa MTs Karolembo dalam berkomunikasi menggunakan dua bahasa, yaitu bahasa Muna sebagai bahasa pertama dan bahasa Indonesia sebagai bahasa kedua. Siswa MTs Karolembo menggunakan bahasa Indonesia hanya di sekolah, sedangkan di rumah atau di lingkungan masyarakat menggunakan bahasa daerah. Hal ini memungkinkan adanya interferensi bahasa Muna ke dalam bahasa Indonesia.

Siswa MTs Karolembo (suku Muna) dalam mengucapkan kata-kata tertentu terkadang melakukan penghilangan fonem atau perubahan fonem dalam bahasa Indonesia sehingga kata yang diucapkan terjadi perubahan bunyi. Hal ini terjadi akibat adanya interferensi bahasa Muna yang dilakukan oleh siswa. Kata tidak diucapkan menjadi tida, hal ini terjadi penghilangan fonem $/ \mathrm{k} /$ di akhir suku kata. Terjadinya pengurangan fonem tersebut dilatarbelakangi oleh pengaruh bahasa daerah Muna ke dalam bahasa Indonesia.

Untuk melihat terjadinya interferensi dapat dilihat adanya kaitan antara kesalahan dan penyimpangan yang dilakukan oleh siswa yang sedang bercerita dengan teman kelasnya dalam lingkungan sekolah. Untuk mengetahui ada dan tidaknya interferensi tersebut, maka penulis melakukan penelitian tentang interferensi fonologis bahasa Muna dalam penggunaan bahasa Indonesia lisan siswa MTs Karolembo.

\subsection{Rumusan Masalah}

Berdasarkan uraian latar belakang tersebut maka yang menjadi masalah dalam penelitian ini adalah:

a. bagaimana interferensi fonologis bahasa Muna dalam penggunaan bahasa Indonesia lisan siswa MTs Karolembo di Kabupaten Muna?

b. faktor apa yang melatarbelakangi terjadinya interferensi fonologis yang dilakukan oleh siswa MTs Karolembo di Kabupaten Muna?

\subsection{Tujuan Penelitian}

Tujuan penelitian ini adalah:

a. untuk mendeskripsikan bentuk interferensi fonologis bahasa Muna yang terjadi dalam penggunaan bahasa Indonesia lisan siswa MTs Karolembo di Kabupaten Muna.

b. untuk mengetahui faktor apa yang meyebabkan terjadinya interferensi fonologis yang dilakukan oleh siswa MTs Karolembo di Kabupaten Muna.

\subsection{Manfaat Penelitian}

Manfaat yang diharapkan dalam penelitian ini adalah sebagai berikut:

a. sebagai bahan masukan bagi siswa MTs Karolembo dalam mengoreksi kesalahan berbahasa yang secara tidak sengaja mereka lakukan. Dengan menyadari kekeliruan yang sering mereka lakukan, siswa MTs Karolembo suku Muna dapat menghilangkan kesalahan berbahasa 
akibat dari pengaruh penggunaan bahasa daerah khususnya bahasa Muna.

b. sebagai usaha memperdalam dan mengembangkan ilmu pengetahuan yang telah diperoleh penulis selama di bangku kuliah.

c. sumbangan data bagi para peneliti selanjutnya, khususnya para peneliti bahasa Muna.

d. latihan bagi penulis untuk berpikir dan bekerja dengan langkah-langkah ilmiah.

\subsection{Batasan Operasional}

a. interferensi adalah adanya saling pengaruh antara bahasa yang satu dengan bahasa yang lain yang bersifat melanggar kaidah dalam berbahasa.

b. fonologis yaitu sifat-sifat bunyi bahasa baik bunyi konsonan maupun bunyi vokal.

c. bahasa Muna dalam penelitian ini adalah bahasa daerah yang digunakan oleh siswa MTs Karolembo sebagai bahasa ibu atau bahasa pertama.

\section{TINJAUAN PUSTAKA}

\subsection{Sosiolinguistik}

Sosiolinguistik sebagai cabang linguistik memandang atau menempatkan kedudukan bahasa dalam hubungannya dengan pemakai bahasa di dalam masyarakat, karena dalam kehidupan bermasyarakat manusia tidak lagi sebagai individu, akan tetapi sebagai masyarakat sosial. Oleh karena itu, segala sesuatu yang dilakukan oleh manusia dalam bertutur akan selalu dipengaruhi oleh sistuasi dan kondisi di sekitarnya. Sebagaimana telah dinyatakan Fisham bahwa sosiolinguistik sebagai ilmu yang bersifat interdisipliner yang menganggap permasalahan kebahasaan dalam hubungannya dengan faktor-faktor sosial, situsional dan kulturalny, (Wijana dan Rohmadi, 2013: 7).

\subsection{Kedwibahasaan/Bilingualisme}

$$
\text { Menurut Rahardi (2010: }
$$

kedwibahasaan atau bilingualisme berkenaan dengan penggunaan dua bahasa atau lebih. Kedwibahasaan tersebut terjadi karena pemakai bahasa telah lebih menguasai bahasa pertamanya atau bahasa ibunya (B1) kemudian menguasai bahasa lainnya sebagai bahasa keduanya (B2). Timbulnya kedwibahasaan dalam suatu masyaratakat karena telah terjadi kontak bahasa antara variasi atau ragam yang lainnya.

\subsubsection{Terjadinya Kedwibahasaan}

Menurut Jendara (dalam khumairoh, 2008: 21-22) terjadinya kedwibahasaan atau bilingualisme dapat disebabkan oleh beberpa hal antara lain 1) adanya bermacam-macam suku bangsa atau bermacam-macam bangsa yang membentuk suatu negara. Orang-orang yang berasal dari berbagai bangsa menetap di suatu daerah baru. Perhubungan antarbangsa yang mendiami daerah itu dilaksanakan dengan media bahasa yang diambil dari salah satu bahasa bangsa itu. 2) Sebagian bangsabangsa yang berbeda yang secara kebetulan mendiami tempat dan tempat itu berdekatan lokasinya dengan daerah bangsa-bangsa yang bersangkutan. 3) Berbagai bangsa bercampur karena menetap di suatu negara daerah baru yang jauh dari asal negara mereka masingmasing.

\subsubsection{Beberapa Cara Mengukur Kedwibahasaan}

W.E. Lamber (dalam Mar'at, 2005: 92) telah mengembangkan suatu alat untuk mengukur kedwibahasaan dengan mencatat hal-hal berikut, a) waktu reaksi seseorang terhadap dua bahasa, b) Kecepatan reaksi dapat diukur pula dari bagaimana seseorang melaksanakan perintah-perintah yang di berikan dalam bahasa yang berbeda, c) Kemampuan seseorang melengkapkan suatu perkataan, dan d) Mengukur kecenderungan (preferences) pengucapan secara spontan.

\subsection{Interferensi}

Interferensi adalah penyimpangan norma bahasa masing-masing yang terjadi di dalam tuturan dwibahasawan sebagai akibat dari pengenalan lebih dari satu dan kontak bahasa itu sendiri. Interferensi dapat dibedakan atas interfernsi morfologis, sintaksis, dan leksikal. Interferensi pada tataran morfologi dan sintaksis biasa disebut interferensi gramatikal, Mardikantoro (2017: 25).

\subsection{Jenis-jenis Interferensi}

Weinreich (dalam Aslinda dan syafiahya, 2010: 66-67) mengidentifikasi jenis-jenis interferensi sebagai berikut: 1) Peminjaman unsur dari aspek satu bahasa ke dalam tuturan bahasa lain. 2) Penggantian unsur dari satu bahasa oleh padanannya di dalam tuturan bahasa lain. Dalam penggantian ini ada aspek dari BI yang disalin dalam bahasa lain. 3) Penerapan hubungan ketatabahasaan bahasa A kedalam morfem bahasa B dalam tuturan bahasa B 
atau pengingkaran hubungan ketatabahasaan bahasa B yang tidak ada modelnya dalam bahasa A. 4) Perubahan fungsi morfem melalui identfikasi antara satu morfem bahasa B tertentu dengan satu morfem bahasa A tertentu yang menimbulkan perubahan (baik perlusan maupun pengurangan) fungsifungsi bahasa $\mathrm{B}$, bedasarkan model tata bahasa A.

\subsection{Bentuk-bentuk Interferensi}

Weinreich (dalam Aslinda dan Syafyahya, 2010:67) juga membagi bentukbentuk interferensi atas tiga bagian, yaitu interferensi dalam bidang fonologi, interferensi dalam bidang leksikal, dan interferensi dalam bidang gramatikal.

\subsection{Faktor \\ Penyebab \\ Timbulnya \\ Interferensi \\ Sejalan dengan pendapat Weinreich} (1970: 64-65) terjadinya interferensi dalam suatu bahasa, antara lain, disebabkan oleh faktor : a) kedwibahasaan para peserta tutur, b) tipisnya kesetiaan pemakai bahasa penerima, c) tidak cukupnya kosakata bahasa penerima dalam menghadapi kemajuan dan pembaharuan, d) menghilangnya kata-kata yang digunakan, e)kebutuhan akan sinonim dan f) prestise bahasa dan gaya bahasa.

\subsection{Pengertian Fonologi}

Menurut Chaer (2009: 1) secara etimologi kata fonologi berasal dari gabungan kata fon yang berarti 'bunyi', dan logi yang berarti 'ilmu'. Sebagai sebuah ilmu fologi lazim diartikan sebagai bagian dari kajian linguistik yang mempelajari, membahas, membicarakan dan menganalisis bunyi-bunyi bahasa yang diproduksi oleh alat-alat ucap manusia. Serupa dengan pendapat Homby (dalam Aslinda dan Syafyahya, 2010: 3) istilah fonologi berasal dari kata phonology, yaitu gabungan kata phone dan logy. Kata phone berarti 'bunyi bahasa, baik berupa bunyi vokal maupun bunyi konsonan; sedangkan kata logy berarti 'ilmu pengetahuan, metode, atau pikiran'.

\subsection{Sistem Fonem Bahsa Indonesia}

Sistem fonem bahasa Indonesia perlu pula di kekumakakan agar dalam perbandingannya dengan bahasa Muna dapat dilihat dengan jelas.
Tabel 1

Sistem fonem vokal bahasa Indonesia

\begin{tabular}{|c|c|c|c|}
\hline & Depan & $\begin{array}{c}\text { Tenga } \\
\mathrm{h}\end{array}$ & Belakang \\
\hline $\begin{array}{c}\text { Tingg } \\
\mathrm{i}\end{array}$ & $\mathrm{I}$ & $\mathrm{u}$ \\
\hline $\begin{array}{c}\text { Teng } \\
\text { ah }\end{array}$ & $\mathrm{E}$ & $\partial$ & $\mathrm{o}$ \\
\hline $\begin{array}{c}\text { Rend } \\
\text { ah }\end{array}$ & & $\mathrm{a}$ & \\
\hline \multicolumn{3}{|c|}{ (Sidu, 2012:6) }
\end{tabular}

Tabel 2

Sistem fonem konsonan bahasa Indonesia

\begin{tabular}{|c|c|c|c|c|c|c|}
\hline \multirow{2}{*}{ CA } & \multicolumn{2}{|c|}{ Labial } & $\begin{array}{c}\text { Alveo } \\
\text { lar }\end{array}$ & $\begin{array}{c}\text { Pala } \\
\text { tal }\end{array}$ & $\begin{array}{c}\text { Vel } \\
\text { ar }\end{array}$ & $\begin{array}{c}\text { Glo } \\
\text { tal }\end{array}$ \\
\cline { 2 - 7 } & $\begin{array}{c}\text { Bila } \\
\text { bial }\end{array}$ & $\begin{array}{c}\text { Lab } \\
\text { iode } \\
\text { ntal }\end{array}$ & & & & \\
\hline Hambat & $\mathrm{p} \mathrm{b}$ & & $\mathrm{t} \mathrm{d}$ & & $\begin{array}{c}\mathrm{k} \mathrm{g} \\
\mathrm{q}\end{array}$ & $?$ \\
\hline Afrikat & & & & $\mathrm{c} \mathrm{j}$ & & \\
\hline Frikatif & & $\mathrm{f} \mathrm{v}$ & $\mathrm{s} \mathrm{z}$ & S & $\mathrm{x}$ & $\mathrm{h}$ \\
\hline Nasal & $\mathrm{m}$ & $\mathrm{n}$ & & $\mathrm{N}$ & $\mathrm{y}$ & \\
\hline Lateral & & & $\mathrm{l}$ & & & \\
\hline Getar & & & $\mathrm{r}$ & & & \\
\hline $\begin{array}{c}\text { Semivo } \\
\text { kal }\end{array}$ & $\mathrm{w}$ & & & $\mathrm{Y}$ & & \\
\hline
\end{tabular}

\subsection{Sistem Fonem Bahasa Muna}

(Sidu, 2012: 7)

Tabel 3

Fonem vokal bahasa Muna

\begin{tabular}{|l|c|c|c|}
\hline & Depan & Tengah & Belakang \\
\hline Tinggi & $\mathrm{I}$ & & $\mathrm{U}$ \\
\hline Sedang & $\varepsilon$ & & $\mathrm{O}$ \\
\hline Rendah & & $\mathrm{a}$ & \\
\hline \multicolumn{4}{|c|}{ (La Ino, 2015: 44) }
\end{tabular}

Tabel 4

Fonem konsonan bahasa Muna

\begin{tabular}{|c|c|c|c|c|c|c|c|}
\hline & $\begin{array}{c}\text { L } \\
\text { ab } \\
\text { ial }\end{array}$ & $\begin{array}{c}\text { labi } \\
\text { ode } \\
\text { ntal }\end{array}$ & $\begin{array}{c}\text { de } \\
\text { nt } \\
\text { al }\end{array}$ & $\begin{array}{c}\text { alve } \\
\text { olar }\end{array}$ & $\begin{array}{c}\text { Pa } \\
\text { lat } \\
\text { al }\end{array}$ & $\begin{array}{c}\text { vela } \\
\mathrm{r}\end{array}$ & $\begin{array}{c}\text { gl } \\
\text { ot } \\
\text { al }\end{array}$ \\
\hline $\begin{array}{c}\text { Hamb } \\
\text { at TB } \\
\text { ekplo } \\
\text { sif }\end{array}$ & P & & & $\mathrm{t}$ & & $\mathrm{k}$ & \\
\hline $\begin{array}{c}\text { B } \\
\text { ekspl } \\
\text { osif }\end{array}$ & B & & & $\mathrm{d}$ & & $\mathrm{g}$ & \\
\hline $\begin{array}{c}\text { Implo } \\
\text { sif }\end{array}$ & B & & ठ & & & & \\
\hline $\begin{array}{c}\text { Geser } \\
\text { an } \\
\text { TB }\end{array}$ & & $\mathrm{f}$ & & $\mathrm{s}$ & & & $\mathrm{h}$ \\
\hline
\end{tabular}




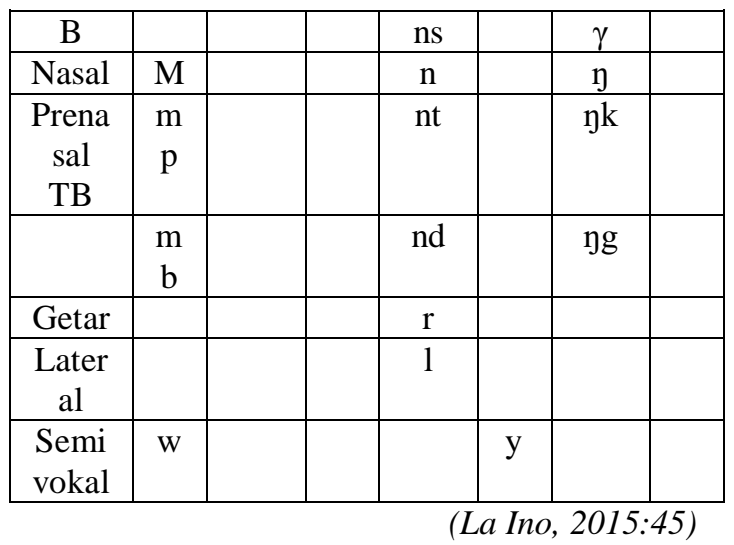

2.10 Distribusi Fonem Bahasa Indonesia 2.10.1 Distribusi Fonem Vokal Bahasa Indonesia

Semua fonem vokal dalam bahasa Indonesia dapat berdistribusi pada semua posisi (awal, tengah, dan akhir kata).

\subsubsection{Distribusi Fonem Konsonan Bahasa} Indonesia

Semua fonem konsonan dapat menduduki posisi awal, tengah, dan akhir, kecuali fonem [w], [j], [c], [g], [q], [̌̌ $],[\check{\mathrm{n}}]$, [v], dan [c] yang tidak dapat menduduki posisi akhir, fonem [y] tidak dapat menduduki posisi awal, dan fonem [y] yang tidak dapat menduduki posisi awal dan posisi akhir.

\subsection{Distribusi Fonem Bahasa Muna}

\subsubsection{Distribusi Fonem Vokal}

Bahasa Muna

Vokal-vokal dalam bahasa Muna dikategorikan berdistribusi lengkap karena kemampuannya menempati posisi awal, tengah, dan akhir kata. Distribusi fonem vokal tersebut dapat ditemukan pada katakata berikut, La Ino (2015: 46).

\subsubsection{Distribusi Fonem Konsonan \\ Bahasa Muna}

Semua fonem konsonan bahasa Muna hanya dapat menduduki posisi awal dan tengah, dengan kata lain tidak dapat menduduki posisi akhir. Selain itu, fonem konsonan bahasa Muna tergolong sebagai bahasa vokalis, Sidu (dalam La Ino 2015: 47).

\section{METODE PENELITIAN}

\subsection{Jenis dan Metode Penelitian \\ 3.1.1 Jenis Penelitian \\ Jenis penelitian ini tergolong penelitian lapangan. Dikatakan penelitian}

lapangan karena peneliti terlibat langsung ke lapangan atau ke sekolah tempat untuk mengumpulkan data penelitian.

\subsubsection{Metode Penelitian}

Adapun metode yang digunakan untuk mengumpulkan dan menganalisis data penelitian ini adalah deskriptif kualitatif. Dikatakan deskriptif karena dalam penelitian ini mendeskripsikan data berdasarkan kenyataan secara objektif sesuai data yang ditemukan. Dikatakan kualitatif karena dalam menjelaskan konsep-konsep yang berkaitan satu sama lain dengan menggunakan katakata atau kalimat bukan menggunakan angkaangka statistik..

\subsection{Data dan Sumber Data}

\subsubsection{Data Penelitian}

Data yang digunakan dalam penelitian ini adalah data lisan. Data lisan yakni data berupa interferensi fonologis bahasa Muna dalam penggunaan bahasa Indonesia lisan siswa MTs Karolembo.

\subsubsection{Sumber Data}

Sumber data penelitian ini adalah semua siswa MTs Karolembo yang berbahasa Muna dan berada di lingkungan sekolah MTs Karolembo. Untuk memperoleh data yang efektif sumber data dalam penelitian ini adalah penutur asli bahasa Muna yang dinilai masih melakukan interferensi dalam bertutur atau berbicara.

Untuk mendapatkan data penelitian, penulis akan mengambil minimal beberapa orang siswa yang akan dijadikan sebagai sumber data. Sumber data dalam penelitian ini adalah siswa yang memenuhi kriteria sebagai berikut:

1. Penutur asli dan fasih menggunakan bahasa Muna dalam kehidupan seharihari.

2. Mengerti dan mampu menggunakan bahasa Indonesia dalam berkomunikasi.

\subsection{Teknik Pengumpulan Data}

Teknik yang digunakan untuk mengumpulkan data tentang interferensi fonologis bahasa Muna dalam pemakaian bahasa Indonesia lisan siswa MTs Karolembo yaitu:

1. Teknik catat yaitu digunakan untuk mencatat hal-hal yang dianggap perlu pada saat pengambilan data.

2. Teknik rekam yaitu proses pengambilan data dari siswa dengan menggunakan alat perekam. Teknik rekam ini digunakan dengan pertimbangan bahwa 
data yang diteliti berupa data lisan untuk mendukung data lisan tersebut maka diperlukan data buatan pada saat pengambilan data.

\subsection{Teknik Analisis Data}

Berikut ini adalah rincian langkahlangkah dalam teknik analisis data yaitu sebagi berikut :

1. transkripsi data merupakan keseluruhan catatan/rekaman bentuk data yang telah dirangkum oleh peneliti setelah melakukan observasi berupa ujaran yang mengalami interferensi fonologis bahasa Muna dalam pemakaian bahasa Indonesia lisan siswa MTs Karolembo.

2. identifikasi data merupakan tahap di mana peneliti memahami data yang telah dirangkum dalam bentuk catatan untuk diamati dan diperiksa serta dipilih dalam hal ini kaitannya bentuk ujaran yang mengalami interferensi.

3. reduksi data merupakan tahap pengelolahan data yang tersedia mana yang merupakan ciri interferensi fonologis bahasa Muna dalam pemakaian bahasa Indonesia lisan yang berupa penghilangan fonem di akhir kata, di tengah kata, dan perubahan fonem, serta faktor-faktor yang mempengaruhi terjadinya interferensi fonologis bahasa Muna dalam pemakaian bahasa Indonesia lisan siswa MTs Karolembo di Kabupaten Muna.

\section{HASIL PENELITIAN DAN \\ PEMBAHASAN}

\subsection{Hasil Penelitian}

Berdasarkan hasil penyeleksian data ditemukan bahwa siswa MTs Karolembo yang sering melakukan interferensi dalam berbicara adalah siswa kelas VII sehingga peneliti hanya mengambil data dari kelas VII saja. Interferensi fonologis yang ditemukan dalam tuturan siswa MTs Karolembo kelas VII berupa penghilangan fonem dan perubahan fonem pada posisi-posisi tertentu saat mereka berbicara dalam bahasa Indonesia.

Sesuai dengan karakteristik masingmasing, data-data hasil penelitian dapat diklasifikasikan sebagai berikut:

1. Penghilangan fonem

a. Penghilangan fonem $/ \mathrm{k} /$ di tengah suku kata b. Penghilangan fonem $/ \mathrm{k} /$ di akhir suku kata

c. Penghilangan fonem $/ \mathrm{h} / \mathrm{di}$ tengah suku kata

d. Penghilangan fonem $/ \mathrm{h} / \mathrm{di}$ akhir suku kata

2. Perubahan fonem

a. Perubahan fonem $/ \mathrm{u} /$ menjadi /o/

b. Perubahan fonem /e/ di tengah suku kata menjadi /a/

c. Perubahan fonem /e/ ditengah suku kata menjadi /u/

d. Perubahan fonem /e/ di tengah suku kata menjadi /i/

e. Perubahan fonem /i/ di tengah suku kata menjadi /e

\subsubsection{Penghilangan Fonem}

4.1.1.1 Penghilangan fonem $/ k$ / di tengah suku kata

Berdasarkan hasil penelitian, peneliti berhasil mengidentifikasi data interferensi fonologis berupa penghilangan fonem $/ \mathrm{k} /$ di tengah suku kata yang terjadi pada kata :

a. Tadi saya lihat kakamu

(seharusnya kakakmu)

b. Bapamu yang mau datang (seharusnya bapakmu)

c. kamu pasti nenemu yang datang (seharusnya nenekmu)

d. mati-matika kayanya (seharunsya kayaknya) dari data tersebut dapat disimpulkan bahwa hal ini merupakan interferensi fonologis yaitu penghilangan fonem $/ \mathrm{k} /$ pada kata kakakmu, bapakmu, nenekmu dan kayaknya. Kaidah penghilangan fonem /k/ di tengah suku kata adalah sebagai berikut : $[-\mathrm{k}-] \rightarrow[-0-]$ artinya pelafalan fonem $/ \mathrm{k} / \mathrm{di}$ tengah suku kata pada kata (kosakata) tertentu menjadi hilang.

\subsubsection{Penghilangan fonem $/ \mathrm{k} / \mathrm{di}$ akhir suku kata}

Berdasarkan hasil penelitian, ditemukan data penghilangan fonrm /k/ di akhir suku kata yang terjadi pada kata :
a. mari kita $d u d u$ di sini (seharusnya duduk)
b. apakah yang busu (seharusnya busuk)
c. sakit saya tatumbuk di meja (seharusnya tertumbuk)
d. tida ada ember (seharusnya tidak) 
e. ...sambalnya banya.

(seharusnya banyak)

f. Kemarin saya beli di ksih satu sendo (seharusnya sendok)

g. Anti kamu yang buang mangko di kantin....? (seharusnya mangkuk)

h. Beso saya tidak datang. (seharusnya besok)

i. ...bisa saya robe satu lembar (seharusnya robek)

Dari data tersebut dapat disimpulkan bahwa hal ini merupakan interferensi fonologis yaitu penghilangan fonem $/ \mathrm{k} / \mathrm{di}$ akhir suku kata, pada kata duduk, busuk, tertumbuk, tidak, banyak, sendok, mangkuk, besok dan robek.

Kaidah penghilangan fonem $/ \mathrm{k} / \mathrm{di}$ akhir suku kata adalah sebagai berikut : $[-\mathrm{k}] \rightarrow[-0]$ artinya pelafalan fonem $/ \mathrm{k} / \mathrm{di}$ akhir suku kata pada kata (kosakata) tertentu menjadi hilang.

\subsubsection{Penghilangan fonem $/ \mathrm{h} / \mathrm{di}$ tengah suku kata}

Berdasarkan hasil penelitian, diperoleh data penghilangan fonem $/ \mathrm{h} / \mathrm{di}$ tengah suku kata yang terjadi pada kata :

a. Mamaku mungkin masalanya bapakku dia sakit. (seharusnya masalahnya)

b. Sampanya lagi siapa yang dihambur....? (seharusnya sampahnya)

c. Teman-teman besok kalian datang di rumaku. (seharusnya rumahku)

d. Tadi saya liat kakakmu.... (seharusnya lihat)

e. ...dia kasikan saya sambalnya banyak. (seharusnya kasihkan)

Dari data tersebut dapat disimpulkan bahwa hal ini merupakan interferensi fonologis yaitu penghilangan fonem $/ \mathrm{h} / \mathrm{di}$ tengah suku kata, pada kata masalahnya, sampahnya, rumahku, lihat dan kasihkan.

Kaidah penghilangan fonem $/ \mathrm{h} / \mathrm{di}$ tengah suku kata adalah sebagai berikut: [-h-] $\rightarrow$ [-0-] artinya pelafalan fonem /h/ di tengah suku kata pada kata (kosakata) tertentu menjadi hilang.

\subsubsection{Penghilangan fonem $/ \mathrm{h} / \mathrm{di}$ akhir suku kata}

Berdasarkan hasil penelitian, diperoleh data penghilangan fonem $/ \mathrm{h} / \mathrm{di}$ akhir suku kata yang terjadi pada kata :

a. ...saya di suru izin besok.

(seharusnya suruh) b. Ok terima kasi Ani

(seharusnya kasih)

c. Kotornya ini sekola. (seharusnya sekolah)

d. Nomor berapa yang sala kamu....? (seharusnya salah)

e. ...bapakku masi lama baru mereka pulnag. (seharusnya masih)

Dari data tersebut dapat disimpulkan

bahwa hal ini merupakan interferensi fonologis yaitu penghilangan fonem $/ \mathrm{h} / \mathrm{di}$ akhir suku kata, pada kata suruh, kasih, sekolah, salah dan masih.

Kaidah penghilangan fonem $/ \mathrm{h} / \mathrm{di}$ akhir suku kata adalah sebagai berikut : $[-\mathrm{h}] \rightarrow[-0]$ artinya pelafalan fonem $/ \mathrm{h} / \mathrm{di}$ akhir suku kata pada kata (kosakata) tertentu menjadi hilang.

\subsubsection{Perubahan Fonem}

\subsubsection{Perubahan fonem /u/ menjadi /o/} Adapun data-data interferensi fonologis dalam aspek perubahan fonem $/ \mathrm{u} /$ menjadi /o/ yaitu:

a. ...saya pergi di pasar di suruh mamaku beli sabo.

(seharusnya sabun)

b. ...dia kurang golanya.

(seharusnya gulanya)

c. Cici jangan kamu coret-coret bokuku....

(seharusnya bukuku).

Gejala perubahan fonem /u/ menjadi /o/ di kaidahkan sebagai berikut : [-u-] $\rightarrow$ [-o-] artinya fonem /u/ di tengah suku kata dalam pelafalnnya berubah menjadi fonem /o/.

\subsubsection{Perubahan Fonem}

4.1.2.2 Perubahan fonem /u/ menjadi /o/ Adapun data-data interferensi fonologis dalam aspek perubahan fonem $/ \mathrm{u} /$ menjadi /o/ yaitu:

d. ...saya pergi di pasar di suruh mamaku beli sabo.

(seharusnya sabun)

e. ...dia kurang golanya.

(seharusnya gulanya)

f. Cici jangan kamu coret-coret bokuku.... (seharusnya bukuku).

Gejala perubahan fonem / $\mathrm{u} /$ menjadi

/o/ di kaidahkan sebagai berikut : $\quad[-\mathrm{u}-]$ $\rightarrow$ [-o-] artinya fonem /u/ di tengah suku kata dalam pelafalnnya berubah menjadi fonem /o/. 


\subsubsection{Perubahan fonem /e/ di tengah suku kata menjadi /a/, fonem /e/ menjadi /u/ dan fonem /e/ menjadi /i/}

Setelah pengidentifikasian data, ditemukan data interferensi perubahan fonem /e/ menjadi /a/, /e/ menjadi /u/ dan /e/ menjadi /i/. Adapun data-data yang dimaksud adalah :

Perubahan fonem /e/ menjadi /a/

a. Boleh saya pinjam karatasimu....?

(seharusnya kertasmu)

b. Biarmi tahamburan begini....

(seharusnya terhamburan)

Kaidah perubahan fonem /e/ menjadi fonem /a/ adalah : [-e-] $\rightarrow[$ [-a- $]$ artinya fonem /e/ di tengah suku kata dalam pelafalannya berubah menjadi fonem /a/.

Perubahan fonem /e/ menjadi / $\mathrm{u} /$

a. Bagusnya supedamu.

(seharusnya sepedamu)

Kaidah perubahan fonem /e/ menjadi fonem /u/ adalah : [-e-] $\rightarrow[-\mathrm{u}-]$ artinya fonem /e/ di tengah suku kata dalam pelafalannya berubah menjadi fonem $/ \mathrm{u} /$.

Perubahan fonem /e/ menjadi /i/

a. Tadi saya kasi pica piring di kantin.

(seharusnya pecah)

b. ...saya lihat pak guru mati-matika

(seharusnya mate-matika)

c. Kita pigi di kantinnya nenek mari! (seharusnya pergi)

Kaidah perubahan fonem /e/ menjadi fonem /i/ adalah : [-e-] $\rightarrow$ [-i-] artinya fonem /e/ di tengah suku kata dalam pelafalannya berubah menjadi fonem /i/.

\subsection{Pembahasan Hasil Penelitian}

Berdasarkan analisis data yang diperoleh dari rekaman percakapan siswa di lingkungan sekolah MTs Karolembo dalam catatan peneliti menunjukan bahwa terjadi interferensi fonolgis bahasa Muna dalam penggunaan bahasa Indonesia lisan pada saat bercerita dengan sesama temannya. Berdasarkan hasil identifikasi dan klasifikasi data, ditemukan jenis interferensi fonologis berupa: (1) penghilangan fonem yang terdiri atas penghilangan fonem $/ \mathrm{k} / \mathrm{dan}$ fonem $/ \mathrm{h} / \mathrm{di}$ tengah suku kata dan di akhir suku kata. Dan (2) perubahan fonem.

\subsubsection{Penghilangan Fonem} 4.2.1.1 Penghilangan fonem di tengah suku kata

Penghilangan fonem di tengah suku kata terjadi pada fonem $/ \mathrm{k} /$ dan fonem $/ \mathrm{h} /$.. Penghilangan fonem $/ \mathrm{k}$ tersebut terjadi pada kata kakakmu, bapakmu, nenekmu dan kayaknya. Dan penghilangan fonem /h/ terjadi pada kata masalahnya, sampahnya, rumahku, lihat dan kasihkan. Hal ini terjadi dalam proses percakapan yang dilakukan oleh siswa pada saat jam istirahat berlangsung yang bertemapt dilingkungan sekolah MTs Karolembo. Keseluruhan data yang diperoleh dari penuturan siswa merupakan penghilangan fonem ditengah suku kata baik fonem $/ \mathrm{k} /$ maupun fonem $/ \mathrm{h} /$. Hal ini terjadi karena dalam struktur kaidah bahasa Muna dikenal dengan KV-KV, V-KV atau $\mathrm{V}$ saja, dan tidak pernah ada struktur KV-KK-V.

\subsubsection{Penghilangan fonem di akhir suku kata}

Penghilangan fonem di akhir suku kata terjadi pada fonem $/ \mathrm{k} /$ dan fonem $/ \mathrm{h} /$. Penghilangan fonem $/ \mathrm{k} /$ tersebut terjadi pada kata duduk, busuk, tertumbuk, tidak, banyak, sendok, mangkuk, besok dan robek. Dan penghilangan fonem /h/ terjadi pada kata suruh, kasih, sekolah, salah dan masih. Keseluruhan data yang diperoleh dari penuturan siswa merupakan penghilangan fonem di akhir suku kata baik fonem $/ \mathrm{k} /$ maupun fonem $/ \mathrm{h} /$. Hal ini terjadi karena dalam struktur kaidah bahasa Muna dikenal dengan $\mathrm{KV}-\mathrm{KV}, \mathrm{V}-\mathrm{KV}$ atau $\mathrm{V}$ saja, dan tidak pernah ada struktur $\mathrm{KV}-\mathrm{KV}-\mathrm{K}$.

\subsubsection{Perubahan Fonem}

\subsubsection{Perubahan fonem /u/ menjadi /o/}

Gejala interferensi perubahan fonem /u/ menjadi fonem /o/ pada kata sabun, gula dan $b u k u$ terjadi karena proses penyelarasan bahasa Muna. Kata sabun dalam bahasa Muna diucapkan dengan osabo, kata gula diucapkan ogola dan kata buku diucapkan oboku sehingga ditemukan salah satu siswa MTs Karolembo dalam mengucapkan kata tersebut menjadi sabo, gola dan boku tetapi hal ini jarang terjadi pada siswa yang lain bahkan selama penelitian peneliti hanya menemukan satu siswa saja yang 
mengucapkan kata tersebut dan hanya pada saat itu juga.

\subsubsection{Perubahan fonem /e/ di tengah suku kata menjadi /a/, fonem /e/ menjadi /u/ dan fonem /e/ menjadi /i/}

Gejala terjadinya interferensi pada perubahan fonem /e/ menjadi fonem /a/, fonem /e/ menjadi fonem /u/ dan fonem /e/ menjadi fonem /i/ disebabkan oleh pengaruh bahasa Muna yang tidak mengenal fonem /e/ taling dalam sistem fonem vokal bahasa Muna hanya mengenal adanya fonem vokal $/ \varepsilon /$ lemah. Sehingga dalam pelafalan pada kata-kata tersebut terjadi perubahan.

\subsection{Klasifikasi Kata (Kosakata) Bahasa Muna yang di Serap Secara Utuh Dari Bahasa Indonesia. \\ Adapun kata (kosakata) bahasa Muna} yang diserap secara utuh dari bahasa Indonesia di antaranya adalah sebagai berikut: palu, radio, remot, tempe, tahu dan kaca.

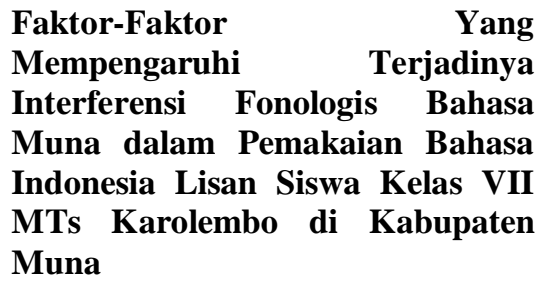

Faktor-faktor yang mempengaruhi siswa melakukan interferensi yaitu:

1) Bahasa yang digunakan siswa dalam lingkungan keluargha adalah dua bahasa yaitu bahasa Muna dan bahasa Indonesia.

2) Seiring perkembangan zaman koasakata yang jarang digunakan dalam bahasa Muna akan hilang sehingga siswa dalam berbicara akan menyerap kosakata dari bahasa Indonesia secara utuh dan siswa tersebut mengira bahwa bahasa yang digunakannya sudah benar.

3) Bahasa yang digunakan siswa dalam situasi belajar di dalam kelas yaitu dua bahasa, bila bertanya kepada temannya menggunakan bahasa Indonesia terkadang juga menggunakan bahasa Muna. Jika bertanya pada guru maka siswa menggunakan bahasa Indonesia.

\subsection{Relevansi Hasil Penelitian \\ Terhadap Pembelajaran Bahasa Indonesia di Sekolah}

Berdasarkan kurilukulum 2013 hasil penelitian tentang "Interferensi fonologis bahasa Muna dalam penggunaan bahasa Indonesia lisan siswa MTs Karolembo di Kabupaten Muna" secara garis besar dapat dijadikan sebagai bahan pelajaran di SMP/MTs kelas VII pada kompetensi dasar dengan materi pokok yaitu Kelebihan dan kekurangan hasil observasi dari aspek isi dan bahasanya secara lisan. Berdasarkan pernyataan tersebut, maka penelitian ini sangat relevan dengan pembelajaran disekolah.

\section{PENUTUP \\ 5.1 Kesimpulan}

Dari beberapa data pada bab IV dapat disimpulkan bahwa interferensi fonologis penghilangan fonem yaitu terdiri atas penghilangan fonem $/ \mathrm{k} /$ dan penghilangan fonem $/ \mathrm{h} /$ baik ditengah suku kata maupun diakhir suku kata.

Interferensi fonologis yang berupa perubahan fonem terdri atas fonem $/ \mathrm{u} /$ berubah menjadi fonem /o/ pada kata sabun menjadi sabo, fonem /e/ menjadi fonem /u/ pada kata sepeda menjadi supeda dan lainlain.

\subsection{Saran}

Berdasarkan simpulan penelitian yang telah dikemukakan di atas, dapatlah disarankan hal-hal sebagai berikut:

1) Guru atau wali kelas siswa kelas VII MTs Karolembo di Kabupaten hendaknya menegaskan bahwa pengurangan fonem dan perubahan foenm baik di awal, di tengah, maupun di akhir kata, fonem vokal maupun fonem konsonan, tidak di benarkan pada saat berbicara dalam bahasa Indonesia.

2) Orang tua siswa hendaknya memberi contoh pula di rumah, bagaimana mengguanakan bahasa Indonesia yang baik dan benar bagi anak-anaknya, termasuk penggunaan bahasa Muna, agar dalam penerapannya, kedua bahasa itu tidak di campur adukan yang pada akhirnya akan menimbulkan penyimpangan atau kesalahan dalam berbahasa. 
3) Agar penelitian tentang interferensi fonologis bahasa Muna dalam bahasa Indonesia lebih lengkap, maka diharapkan setelah penelitian ini ada peneliti-peneliti selanjutnya yang dapat meneliti secara mendalam tentang penggunaan bahasa Indonesia yang baik dan benar, baik dalam morfologis, bidang sintaksis, bidang leksikal maupun pada bidang makna.

4) Guru atau wali kelas sebaiknya mempelajari dan mengidentifikasi kasuskasus interferensi fonologis bahasa Muna dalam bahasa Indonesia agar memudahkan ia untuk menentukan metode dan teknik pembelajaran yang tepat untuk mengajarkan kedua bahasa itu (bahasa Indonesia dan bahasa Muna).

\section{DAFTAR PUSTKA}

Achmad dan Alek Abdullah. 2012. Linguistik Umum. Jakarta: Erlangga.

Aslinda dan Leni Syafyahya. 2010. Pengantar Sosiolingustik. Bandung: PT Refika Aditama

Chaer, Abdul. 2007. Linguistik Umum. Jakarta: Rineka Cipta.

Chaer, Abdul. 2009. Fonologi Bahasa Indonesia. Jakarta: Rineka Cipta.

Chaer, Abdul dan Leonie Agustina. 2010. Sosiolingustik Perkenalan Awal. Jakarta: Rineka Cipta

Darini S Annura Wulan. 2015. Interferensi Fonologi, Morfologoi, dan Leksikal dalam Komunikasi Formal Mahasiswa Sastra Indonesia Fakultas Ilmu Budaya Universitas Airlangga. Jurnal skriptorium, Vol. 1, No. 3.

https://www.google.com/amp/s/bagawanabiy asa.wordpress.com/2016/08/14/interfere nsi-dan-integrasi-bahasa/amp

Kasim, Kristin. 2003. Interferensi Fonologi Bahasa Gorontalo terhadap Penggunaan Bahasa Indonesia Siswa Kelas III SLTP Negeri Boalemo. Skripsi. Kendari: FKIP Unhalu.

Komariah, Siti. 2008. Interferensi Bahasa Inggris dalam Bahasa Indonesia pada Surat Kabar di Surabaya. Surabaya: Balai Bahasa Surabaya

Kuwing, Miss Aseeyah. 2016. Interferensi Fonologi Bahasa Melayu Pattani dalam \begin{tabular}{llr} 
Berbahasa Indonesia & Mahasiswa \\
Thailand & di & Universitas \\
Muhammadiyah & Surakarta. & Artikel \\
Publikasi. & \multicolumn{2}{c}{}
\end{tabular}

La Ino. 2015. Deskripsi Fonem Bahasa di Sulawesi Tenggara. Yogyakarta: Pustaka Puitika.

Mar'at, Samsunuwiyati. 2005. Psikolinguistik. Bandung: PT Refika Aditama.

Mardikantoro, Hari Bakti. 2017. Samin Kajian Sosiolinguistik Bahasa Persaudaraan dan Perlawanan. Yogyakarta: Forum.

Padmadewi, Ni Nyoman, dkk. 2014. Sosiolinguistik. Yogyakarta: Graha Ilmu.

Pateda, Mansoer. 1987. Sosiolinguistik. Bandung: Angkasa.

Putrayasa, Ida Bagus. 2014. Pragmatik. Yogyakarta: Graha Ilmu.

Rahardi, Kunjana. 2010. Kajian Sosiolinguistik, Bogor: Ghalia Indonesia.

Sidu, La Ode. 2012. Sintaksis Bahasa Indonesia. Kendari: Unhalu Press.

Suwandi, Sarwiji. 2008. Sosiolinguistik Mengupas Pelbagai Praktik Berbahasa. Surakrta: LPP UNS dan UNS PRES.

Tarigan, Henry Guntur. 1988. Pengajaran Kedwibahasaan. Bandung: Angkasa.

Wijana, I Dewa Putu dan Muhammad Rohmadi. 2013. Sosiolinguistik. Yogyakarta: Pustaka Pelajar. 